\title{
Separation of methanol + dimethyl carbonate azeotropic mixture Using ionic liquids as entrainers
}

\author{
Zhigang Zhang, Honghong Xu, Qinqin Zhang ${ }^{*}$, Aidi Zhang, Yue Li, Wenxiu Li ${ }^{*}$ \\ Liaoning Provincial Key Laboratory of Chemical Separation Technology, Shenyang University of \\ Chemical Technology, Shenyang, 110142, China.
}

\begin{abstract}
Isobaric vapor-liquid equilibrium (VLE) data of methanol + dimethyl carbonate, methanol + dimethyl carbonate + 1-Ethyl-3-Methylimidazolium Bromide $([\mathrm{EMIM}][\mathrm{Br}])$ and methanol + dimethyl carbonate + 1-Butyl-3-Methylimidazolium Chloride ([BMIM][Cl]) were measured by a modified Othmer still at $101.3 \mathrm{kPa}$. The two investigated ionic liquids produced significant effects on the separation of the methanol and dimethyl carbonate azeotropic system. The relative volatility of dimethyl carbonate to methanol was enhanced with the addition of ionic liquid. The two ionic liquids could both eliminate the azeotropic point as their concentration increased to a certain value, but $[\mathrm{BMIM}][\mathrm{Cl}]$ showed a greater separation effect on methanol and dimethyl carbonate azeotropic system than [EMIM][Br]. Furthermore, the measured data were well correlated with the nonrandom two-liquid (NRTL) model.
\end{abstract}

Keywords: vapor-liquid equilibrium, ionic liquids, methanol, dimethyl carbonate, NRTL model

* Corresponding Author: Wenxiu Li, Email address: wenxli@126.com, Fax: 86-24-89383736; Qinqin Zhang, Email address: zhangshoudao@ 126.com, Fax: 86-24-89383736 1 


\section{Introduction}

Dimethyl carbonate (DMC) has been a high-profile agent in recent years because of its excellent properties and extensive applications [1-7]. For example, DMC has favorable solubility and nontoxicity which make it an environmentally friendly solvent. Due to its high oxygen content, DMC could be used as gasoline additives to improve octane number. As a basic organic raw material, methanol has a very wide range of applications [8], such as medicine, solvent, and organic synthesis. In the synthesis process of DMC, methanol is one of the raw materials. Due to the use of excessive methanol, DMC and methanol could form azeotrope which is difficult to be separated.

For separating azeotropic systems, extractive distillation [9-11] is an efficient method and the selection of entrainer is the key to it. Inorganic salts [12-14] and organic solvents [15-16] are traditionally used as entrainers but some bad influence could be caused. For example, the use of inorganic salts could lead to pipeline corrosion and organic solvents may cause environmental pollution and water pollution. Ionic liquids (ILs) as new entrainers have become more and more popular in recent years because of their unique properties, such as negligible vapor pressure, good chemical and thermal stability and tunable structures [17-18]. Now, plenty of ILs have been employed as entrainers to separate azeotropes and their performances reported in literature are uplifting. Zhang et al. [19] investigated the ternary systems of methyl acetate and methanol containing 1-butyl-3-methylimidazolium chloride ([ $\left.\left.\mathrm{C}_{4} \mathrm{MIM}\right][\mathrm{Cl}]\right)$, or 1-(2-chloroethyl)-3-methylimidazolium chloride $\left(\left[\mathrm{ClC}_{2} \mathrm{MIM}\right][\mathrm{Cl}]\right)$, 
or 1-butyl-3-methylimidazolium bromide ([C $\left.\left.\mathrm{C}_{4} \mathrm{MIM}\right][\mathrm{Br}]\right)$. Li et al. [20 21] measured the VLE data based on methanol and DMC containing 1-octyl-3-methylimidazolium tetrafluoroborate $\left([\mathrm{OMIM}]\left[\mathrm{BF}_{4}\right]\right)$, or 1-ethyl-3-methylimidazolium trifluor ([EMIM][OTf]), or 1-buthyl-3-methylimidazolium trifluor ([BMIM][OTf]). Cai and Chen et al. [22 23] compared the separation effect of different phosphoric-based ionic liquids on the mixture of methanol and DMC. Ales Blahut et al. [24] studied the effect of 1-ethyl-3-methylimidazolium tetracyanoborate ([EMIM][TCB]) on the azeotropic system of methanol + DMC. The VLE data for the system DMC +methanol with different concentration of 1-buthyl-3-methylimidazolium tetrafluoroborate $\left([\mathrm{BMIM}]\left[\mathrm{BF}_{4}\right]\right)$ and 1-ethyl-3-methylimidazolium ethyl sulfate (EMISE) were measured by Hyeon-Deok Kim et al. [25]. [BMIM][Cl] has been tried to separate the azeotropic mixture of methanol and DMC, but only a speculative conclusion that $[\mathrm{BMIM}][\mathrm{Cl}]$ has remarkable azeotrope breaking capacity was made and no details was given [26].

In this work, two ILs, namely $[\mathrm{EMIM}][\mathrm{Br}]$ and $[\mathrm{BMIM}][\mathrm{Cl}]$, were used as entrainers to separate methanol and DMC mixture at $101.3 \mathrm{kPa}$. The separation effects of these two ionic liquids were compared and the reason for their different performance was analyzed.

\section{Experimental section}

\subsection{Chemicals.}

In this experiment, the solvents were methanol, DMC, [EMIM][Br], and [BMIM][Cl]. Methanol and DMC were purchased from Sinopharm group and 
examined by gas chromatography. The results proved that their mass fraction was higher than 99.5\%. [EMIM][Br] and [BMIM][Cl] were obtained from our own laboratory. Their purities were greater than 99\% (mass fraction) which were authenticated by liquid chromatography (Wayee IC6000). The water content checked by Karl Fischer was lower than 0.005 (mass fraction). The ILs were dried at $373 \mathrm{~K}$ under vacuum for $48 \mathrm{~h}$ before use. The specifications of all the chemicals used in this work are listed in Table 1.

\section{Table 1}

The specifications of the chemical samples

\begin{tabular}{lllll}
\hline Chemical name & Source & purity & Purification method & Analysis method \\
\hline methanol & SinopharmGroup & 0.995 & None & GC $^{\mathrm{a}}$ \\
DMC & SinopharmGroup & 0.995 & None & $\mathrm{GC}^{\mathrm{a}}$ \\
& Prepared in this & & & \\
{$[\mathrm{BMIM}][\mathrm{Cl}]$} & work & 0.990 & Vacuum desiccation & $\mathrm{LC}^{\mathrm{c}} \mathrm{KF}^{\mathrm{b}}$ \\
& Prepared in this & & & \\
{$[\mathrm{EMIM}][\mathrm{Br}]$} & work & 0.990 & Vacuum desiccation & $\mathrm{LC}^{\mathrm{c}} \mathrm{KF}^{\mathrm{b}}$ \\
\hline
\end{tabular}

${ }^{\mathrm{a}} \mathrm{GC}=$ gas chromatography.

${ }^{\mathrm{b}} \mathrm{KF}=$ Karl Fisher titration.

${ }^{\mathrm{c}} \mathrm{LC}=$ liquid chromatography

\subsection{Apparatus and procedure}

In this experiment, an all-glass dynamic recirculating still (NGW, Wertheim, Germany) described in the previous literature[27] was used to measure the VLE data. This apparatus is mainly composed of heating, cooling, sampling and other parts. Among them a Heating rod was used to heat the apparatus, and a spherical condenser with tap water as condensing medium was used to ensure backflow. The pressure of this apparatus was measured by a manometer whose uncertainty was $0.1 \mathrm{kPa}$ and kept 
constant at $101.3 \mathrm{kPa}$ by controlling the pressure of a gas buffer connected to the device. The temperature of this still was measured by a thermometer with a standard uncertainty of $0.01 \mathrm{~K}$.

The experiment data of the binary system of methanol + DMC were obtained by continuously adding methanol to DMC until the mole fraction of DMC was less than 0.04. For the ternary system, a mixture of DMC with a certain mole fraction of IL was prepared firstly and then a mixture of methanol with the same mole fraction of IL was added to the former. Only when the system temperature was constant for more than 30 minutes, could we take the samples of vapor and liquid to analyze.

\subsection{Samples analysis}

The condensed vapor and liquid phase samples were first inserted into a headspace sampler (G1888 Network headspace sampler, Agilent Technologies) and then analyzed by a gas chromatography (Model 7890A, Agilent Technologies). The GC is equipped with an Agilent 19091J-413 capillary column (30 m in length, $0.32 \mathrm{~mm}$ in diameter and $2.5 \mu \mathrm{m}$ in thickness) and a TCD detector. The carrier gas was $\mathrm{H}_{2}$. The operating conditions were as follows: the temperatures of injector, oven and detector were $473 \mathrm{~K}, 353 \mathrm{~K}$ and $473 \mathrm{~K}$, respectively. The IL content of each liquid sample was measured by calculating the mass difference before and after vaporizing the volatile component in a vacuum desiccator. Each sample was analyzed at least three times. The standard uncertainty of the mole fraction of the components in the liquid and vapor phase is 0.001 .

3. Results and discussion 


\subsection{Experimental data}

The VLE data of the binary system of methanol + DMC were measured to check the reliability of our apparatus. Detailed data are shown in Table 2, where $T$ is equilibrium temperature, $x_{1}$ is the mole fraction of methanol in the liquid phase and $y_{1}$ is the mole fraction of methanol in the vapor phase. It is obvious in Fig. 1 that the experimental data agree well with the data calculated by the NRTL model and the data in literature $[20,23]$. Therefore, the apparatus in this work is reliable.

\section{Table 2}

The isobaric VLE data for the binary system of methanol (1) + DMC (2) at $101.3 \mathrm{kPa}$.

\begin{tabular}{lll}
\hline$T / \mathrm{K}$ & $x_{1}$ & $y_{1}$ \\
\hline 354.45 & 0.060 & 0.287 \\
351.95 & 0.085 & 0.353 \\
348.20 & 0.134 & 0.455 \\
343.00 & 0.251 & 0.590 \\
340.85 & 0.337 & 0.654 \\
339.20 & 0.443 & 0.706 \\
338.00 & 0.570 & 0.740 \\
337.15 & 0.719 & 0.794 \\
337.00 & 0.772 & 0.810 \\
336.85 & 0.845 & 0.844 \\
336.85 & 0.868 & 0.868 \\
336.95 & 0.912 & 0.895 \\
337.10 & 0.946 & 0.928 \\
337.25 & 0.967 & 0.958 \\
\hline
\end{tabular}

Standard uncertainty $u\left(x_{1}\right)=u\left(y_{1}\right)=0.001, u(T)=0.01 \mathrm{~K}$ 


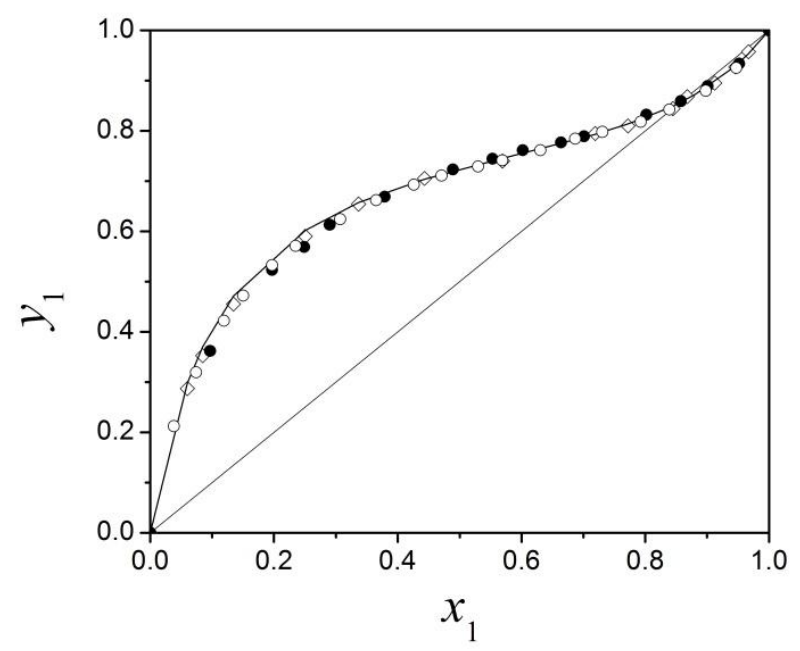

Fig. 1. Isobaric VLE diagram for the binary system of methanol (1) + DMC (2) at $101.3 \mathrm{kPa} . \circ$, from Ref [23]; •, from Ref [20]; $\diamond$, this work; solid line, the data correlated with the NRTL model.

The experimental data of the ternary systems methanol (1) + DMC (2) + $[\mathrm{EMIM}][\mathrm{Br}](3)$ and methanol (1) + DMC (2) + [BMIM][Cl] (3) were obtained at $101.3 \mathrm{kPa}$. The mole fraction of [EMIM][Br] was kept at $0.1,0.2$, and 0.25 , while [BMIM][Cl] 0.1, 0.15, and 0.2. The data are listed in Tables 3-4, where $T$ is equilibrium temperature of ternary system, $x_{3}$ is the mole fraction of IL in liquid phase, $x_{1}$ is the mole fraction of methanol in liquid phase, $x_{1}{ }^{\prime}$ is the mole fraction of methanol on an IL-free basis in liquid phase, and $y_{1}$ is the mole fraction of methanol in vapor phase. 
Table 3

The isobaric VLE data for the ternary system of methanol (1) + DMC (2) + [EMIM][Br] (3) at $101.3 \mathrm{kPa}$.

\begin{tabular}{|c|c|c|c|c|c|}
\hline$T / \mathrm{K}$ & $x_{3}$ & $x_{1}$ & $x_{1}{ }^{\prime}$ & $y_{1}$ & $\alpha_{12}$ \\
\hline 357.85 & 0.11 & 0.073 & 0.082 & 0.112 & 1.410 \\
\hline 354.10 & 0.11 & 0.153 & 0.171 & 0.233 & 1.472 \\
\hline 351.65 & 0.11 & 0.208 & 0.233 & 0.304 & 1.441 \\
\hline 347.25 & 0.10 & 0.325 & 0.362 & 0.435 & 1.359 \\
\hline 345.15 & 0.10 & 0.396 & 0.441 & 0.499 & 1.264 \\
\hline 343.80 & 0.10 & 0.450 & 0.502 & 0.534 & 1.136 \\
\hline 342.15 & 0.10 & 0.532 & 0.593 & 0.601 & 1.033 \\
\hline 341.35 & 0.11 & 0.583 & 0.651 & 0.651 & 0.999 \\
\hline 340.55 & 0.10 & 0.639 & 0.713 & 0.699 & 0.936 \\
\hline 339.95 & 0.11 & 0.731 & 0.819 & 0.780 & 0.784 \\
\hline 339.85 & 0.11 & 0.773 & 0.865 & 0.818 & 0.699 \\
\hline 340.10 & 0.10 & 0.855 & 0.951 & 0.911 & 0.532 \\
\hline 353.00 & 0.21 & 0.078 & 0.099 & 0.057 & 0.551 \\
\hline 352.45 & 0.20 & 0.112 & 0.140 & 0.090 & 0.606 \\
\hline 350.35 & 0.20 & 0.181 & 0.225 & 0.153 & 0.623 \\
\hline 347.85 & 0.21 & 0.269 & 0.339 & 0.253 & 0.661 \\
\hline 345.95 & 0.21 & 0.352 & 0.443 & 0.342 & 0.652 \\
\hline 344.45 & 0.20 & 0.440 & 0.548 & 0.432 & 0.629 \\
\hline 343.20 & 0.20 & 0.526 & 0.657 & 0.531 & 0.589 \\
\hline 342.70 & 0.20 & 0.586 & 0.733 & 0.605 & 0.558 \\
\hline 342.60 & 0.20 & 0.670 & 0.837 & 0.727 & 0.519 \\
\hline 343.15 & 0.20 & 0.722 & 0.903 & 0.824 & 0.504 \\
\hline 344.10 & 0.21 & 0.757 & 0.954 & 0.895 & 0.412 \\
\hline 351.00 & 0.25 & 0.054 & 0.073 & 0.026 & 0.344 \\
\hline 350.00 & 0.25 & 0.076 & 0.102 & 0.041 & 0.379 \\
\hline 348.60 & 0.25 & 0.142 & 0.189 & 0.085 & 0.400 \\
\hline 347.35 & 0.25 & 0.205 & 0.274 & 0.144 & 0.445 \\
\hline 346.15 & 0.25 & 0.282 & 0.377 & 0.237 & 0.514 \\
\hline 345.45 & 0.25 & 0.329 & 0.439 & 0.282 & 0.503 \\
\hline 344.75 & 0.25 & 0.382 & 0.510 & 0.345 & 0.505 \\
\hline 344.15 & 0.25 & 0.441 & 0.589 & 0.418 & 0.502 \\
\hline 343.85 & 0.25 & 0.491 & 0.655 & 0.483 & 0.492 \\
\hline 343.75 & 0.25 & 0.545 & 0.727 & 0.558 & 0.473 \\
\hline 343.95 & 0.25 & 0.605 & 0.807 & 0.653 & 0.449 \\
\hline 344.35 & 0.25 & 0.638 & 0.852 & 0.709 & 0.424 \\
\hline 345.50 & 0.24 & 0.719 & 0.948 & 0.876 & 0.387 \\
\hline 346.65 & 0.25 & 0.730 & 0.975 & 0.935 & 0.376 \\
\hline
\end{tabular}

Standard uncertainty $u\left(x_{1}{ }^{\prime}\right)=u\left(x_{1}\right)=u\left(y_{1}\right)=0.001, u(T)=0.01 \mathrm{~K}$ 
Table 4

The isobaric VLE data for the ternary system of methanol (1) + DMC (2) + [BMIM][Cl] (3) at $101.3 \mathrm{kPa}$.

\begin{tabular}{|c|c|c|c|c|c|}
\hline$T / \mathrm{K}$ & $x_{3}$ & $x_{1}$ & $x_{1}^{\prime}$ & $y_{1}$ & $\alpha_{12}$ \\
\hline 361.35 & 0.11 & 0.030 & 0.034 & 0.034 & 0.986 \\
\hline 357.00 & 0.11 & 0.105 & 0.118 & 0.120 & 1.017 \\
\hline 354.25 & 0.11 & 0.168 & 0.189 & 0.216 & 1.185 \\
\hline 351.65 & 0.12 & 0.233 & 0.265 & 0.269 & 1.024 \\
\hline 350.00 & 0.12 & 0.278 & 0.315 & 0.302 & 0.941 \\
\hline 346.60 & 0.11 & 0.386 & 0.436 & 0.453 & 1.072 \\
\hline 344.55 & 0.11 & 0.464 & 0.521 & 0.511 & 0.962 \\
\hline 343.35 & 0.11 & 0.522 & 0.587 & 0.545 & 0.844 \\
\hline 342.25 & 0.11 & 0.584 & 0.656 & 0.613 & 0.830 \\
\hline 341.15 & 0.11 & 0.683 & 0.769 & 0.682 & 0.642 \\
\hline 340.85 & 0.11 & 0.764 & 0.861 & 0.776 & 0.562 \\
\hline 341.10 & 0.11 & 0.835 & 0.937 & 0.866 & 0.432 \\
\hline 354.45 & 0.16 & 0.094 & 0.112 & 0.069 & 0.591 \\
\hline 353.65 & 0.16 & 0.152 & 0.181 & 0.112 & 0.569 \\
\hline 350.55 & 0.17 & 0.237 & 0.285 & 0.193 & 0.601 \\
\hline 348.15 & 0.17 & 0.327 & 0.392 & 0.283 & 0.614 \\
\hline 346.45 & 0.16 & 0.397 & 0.472 & 0.353 & 0.610 \\
\hline 345.15 & 0.16 & 0.461 & 0.552 & 0.430 & 0.611 \\
\hline 344.25 & 0.16 & 0.515 & 0.613 & 0.486 & 0.598 \\
\hline 343.60 & 0.17 & 0.575 & 0.691 & 0.557 & 0.564 \\
\hline 342.95 & 0.16 & 0.684 & 0.817 & 0.689 & 0.497 \\
\hline 343.15 & 0.16 & 0.735 & 0.877 & 0.764 & 0.456 \\
\hline 344.20 & 0.16 & 0.791 & 0.947 & 0.879 & 0.412 \\
\hline 352.55 & 0.20 & 0.122 & 0.154 & 0.069 & 0.406 \\
\hline 351.35 & 0.20 & 0.173 & 0.216 & 0.105 & 0.425 \\
\hline 349.25 & 0.21 & 0.233 & 0.294 & 0.150 & 0.423 \\
\hline 347.55 & 0.21 & 0.316 & 0.398 & 0.219 & 0.424 \\
\hline 346.45 & 0.22 & 0.372 & 0.478 & 0.273 & 0.410 \\
\hline 345.65 & 0.22 & 0.435 & 0.555 & 0.341 & 0.416 \\
\hline 345.15 & 0.21 & 0.487 & 0.618 & 0.416 & 0.441 \\
\hline 344.55 & 0.20 & 0.569 & 0.715 & 0.520 & 0.433 \\
\hline 344.85 & 0.21 & 0.640 & 0.809 & 0.623 & 0.392 \\
\hline 345.45 & 0.21 & 0.699 & 0.880 & 0.732 & 0.371 \\
\hline 346.50 & 0.21 & 0.737 & 0.931 & 0.826 & 0.352 \\
\hline
\end{tabular}

Standard uncertainty $u\left(x_{1}{ }^{\prime}\right)=u\left(x_{1}\right)=u\left(y_{1}\right)=0.001, u(T)=0.01 \mathrm{~K}$. 


\subsection{Calculation of the phase equilibrium}

This experiment was carried out at $101.3 \mathrm{kPa}$, so the assumption of ideal vapor-phase could be made. The equilibrium equation is written as follows:

$y_{i} P=x_{i} \gamma_{i} P_{i}^{S}$

where $y_{\mathrm{i}}$ represents the mole fraction of the component $i$ in the vapor phase; $\mathrm{P}$ represents the total pressure $\left(101.3 \mathrm{kPa}\right.$ in this work); $x_{i}$ represents the mole fraction of the component $i$ in the liquid phase; $P_{i}^{\mathrm{S}}$ is the saturated vapor pressure of component $i$ at the equilibrium temperature which could be calculated by the Antoine equation.

$\log \left(P_{i}^{S} / k P a\right)=A-B /(T / K+C)$

where $\mathrm{A}, \mathrm{B}$ and $\mathrm{C}$ are antoine parameters; $T$ is equilibrium temperature of ternary system. The parameters (A, B and C) of this equation are listed in Table 5.

\section{Table 5}

Antoine parameters for methanol and DMC.

\begin{tabular}{llllll}
\hline \multirow{2}{*}{ Component } & \multicolumn{2}{l}{ Antoine parameters } & \multicolumn{3}{c}{ Temperature range } \\
\cline { 2 - 6 } & $A_{\mathrm{i}}$ & $B_{\mathrm{i}}$ & $C_{\mathrm{i}}$ & $\mathrm{Min} /(\mathrm{K})$ & $\operatorname{Max} /(\mathrm{K})$ \\
\hline DMC $^{\mathrm{a}}$ & 6.4338 & 1413.00 & -44.25 & 273.15 & 548.0 \\
Methanol $^{\mathrm{b}}$ & 7.14736 & 1544.804 & -37.235 & 335.0 & 376.0 \\
\hline
\end{tabular}

${ }^{\mathrm{a}}$ from ref [21], ${ }^{\mathrm{b}}$ from ref [28]

At present, the nonrandom two-liquid (NRTL) activity coefficient model is usually used to correlate and predict the VLE data of the IL-containing systems and the results are quite satisfactory [29]. NRTL model is expressed by the following equation:

$$
\begin{aligned}
& \ln \gamma_{i}=\frac{\sum_{j=1}^{N} \tau_{j i} G_{j i} x_{j}}{\sum_{k=1}^{N} G_{k i} x_{k}}+\sum_{j=1}^{N} \frac{x_{j} G_{i j}}{\sum_{j=1}^{N} G_{k i} x_{k}}\left[\tau_{i j}-\frac{\sum_{k=1}^{N} G_{k j} x_{k} \tau_{k j}}{\sum_{k=1}^{N} G_{k j} x_{k}}\right] \\
& \tau_{j i}=\frac{\Delta g_{j i}}{R T}, \quad G_{j i}=\exp \left(-\alpha_{j i} \tau_{j i}\right)
\end{aligned}
$$


where $\gamma_{i}$ is the activity coefficient of component $i, x_{j}, x_{i}$ and $x_{k}$ are the mole fractions of components $j, i$ and $k, \Delta g_{j i}$ is the binary interaction parameter, and $\mathrm{T}$ is the equilibrium temperature. The model parameters are obtained by minimizing the average relative deviation (ARD) which is calculated according to the following equation:

$\operatorname{ARD}(\%)=\frac{1}{n} \sum_{i=1}^{n}\left|\frac{\gamma_{i}^{\text {exptl }}-\gamma_{i}^{\text {calcd }}}{\gamma_{i}^{\text {exptl }}}\right| \times 100$

where $n$ is the number of experiment point, $\gamma_{i}$ is the activity coefficient of component $i$, and the superscripts "exptl" and "calcd" represent the experimental and calculated values, respectively. In this work, the NRTL model is also used to correlate the experimental VLE data and the correlated results are listed in Table 6.Then the mean absolute deviations and standard deviations between experimental and calculated values of vapor phase mole fractions and the VLE temperature are listed in Table 7. The results indicate that the NRTL model is suitable to correlate the experimental data.

\section{Table 6}

Estimated values of non-randomness factors $\alpha_{\mathrm{i}, \mathrm{j}}$ and binary energy parameters $\Delta \mathrm{g}_{i, j}, \Delta \mathrm{g}_{j, i}$, for the NRTL model.

\begin{tabular}{llllll}
\hline Component $i$ & Component $j$ & $\alpha_{\mathrm{i}, \mathrm{j}}$ & $\frac{\Delta g_{i, j}}{J / m o l}$ & $\frac{\Delta g_{j, i}}{J / m o l}$ & $\frac{\text { ARD }}{\%}$ \\
\hline methanol & DMC & $0.300^{\mathrm{a}}$ & $3115.2^{\mathrm{a}}$ & $833.1^{\mathrm{a}}$ & 1.98 \\
methanol & {$[\mathrm{EMIM}][\mathrm{Br}]$} & 0.277 & 650.6 & 2947 & 1.81 \\
DMC & {$[\mathrm{EMIM}][\mathrm{Br}]$} & 0.092 & 25867 & -2432.5 & \\
methanol & {$[\mathrm{BMIM}][\mathrm{Cl}]$} & 0.227 & 110.2 & -6012.78 & 2.96 \\
DMC & {$[\mathrm{BMIM}][\mathrm{Cl}]$} & 0.079 & 26667.5 & -4432.5 & \\
\hline
\end{tabular}

${ }^{\mathrm{a}}$ From ref. [23], $\Delta g_{\mathrm{i}, \mathrm{j}}=g_{\mathrm{i}, \mathrm{j}^{-}} g_{\mathrm{i}, \mathrm{i}}, \tau_{\mathrm{ij}}=\left(g_{\mathrm{i}, \mathrm{j}^{-}} g_{\mathrm{i}, \mathrm{i}}\right) / \mathrm{R} T$ 


\section{Table 7}

Mean absolute deviations $\delta \mathrm{y}, \delta \mathrm{T}$, and standard deviations $\sigma \mathrm{y}, \sigma \mathrm{T}$, between experimental and calculated values of vapor phase mole fractions and the VLE temperature

\begin{tabular}{lllll}
\hline system & $\delta y^{a}$ & $\sigma y^{b}$ & $\delta T^{c}(K)$ & $\sigma T^{c}(K)$ \\
\hline Methanol + DMC & 0.0068 & 0.0081 & 0.03 & 0.05 \\
Methanol + DMC + [EMIM]Br & 0.0067 & 0.0058 & 0.04 & 0.07 \\
Methanol + DMC + [BMIM]Cl & 0.0065 & 0.0083 & 0.07 & 0.08 \\
\hline
\end{tabular}

$n$ is the number of experimental points.

${ }^{\mathrm{a}} \delta \mathrm{y}=(1 / n) \sum\left|y_{\text {exptl }}-y_{\text {calcd }}\right|{ }^{\mathrm{b}}$ oy $=\left[\sum\left(y_{\text {exptl }}-y_{\text {calcd }}\right)^{2} /(n-1)\right]^{1 / 2}$,

${ }^{\mathrm{c}} \delta \mathrm{T}=(1 / n) \sum\left|T_{\text {exptl }}-T_{\text {calcd }}\right|,{ }^{\mathrm{d}} \sigma \mathrm{T}=\left[\sum\left(T_{\text {exptl }}-T_{\text {calcd }}\right)^{2} /(n-1)\right]^{1 / 2}$.

The Figs. 2-3 show the $y_{1}-x_{1}{ }^{\prime}$ diagrams of the ternary systems of methanol (1) + $\mathrm{DMC}(2)+[\mathrm{EMIM}][\mathrm{Br}](3)$ or $[\mathrm{BMIM}][\mathrm{Cl}](3)$. It can be seen that experimental data are in good agreement with the correlated data. What's more, with the addition of IL the content of methanol in the liquid becomes larger. With increasing the amount of IL, the azeotropic point moves down and disappears as the mole fractions of [EMIM][Br] and [BMIM][Cl] are increased to 0.2 and 0.15 , respectively. According to the NRTL model, to completely break the azeotropic point of methanol and DMC system the minimum mole fraction of $[\mathrm{EMIM}][\mathrm{Br}]$ is 0.1461 while that of $[\mathrm{BMIM}][\mathrm{Cl}]$ only need to reach 0.1168 . Thus, it can be concluded that $[\mathrm{BMIM}][\mathrm{Cl}]$ has better separation effect than [EMIM] $[\mathrm{Br}]$. 


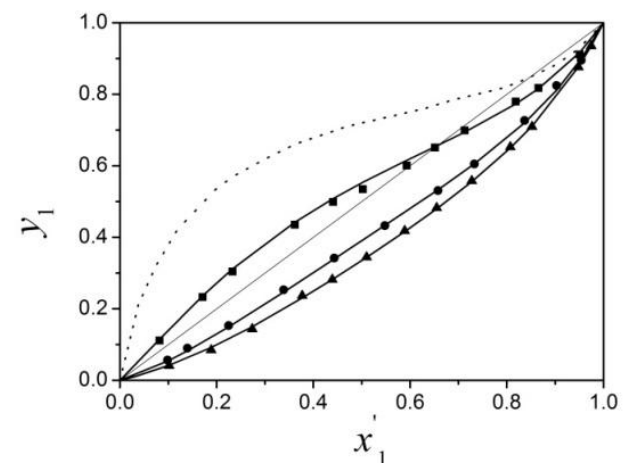

Fig. 2. Isobaric $y_{1}-x_{1}{ }^{\prime}$ diagram for the methanol (1) + DMC (2) + [EMIM] $[\mathrm{Br}](3)$ ternary system at $101.3 \mathrm{kPa}$ : dotted line, IL-free system; $-x_{3}=0.1 ; \bullet, x_{3}=0.2 ; \boldsymbol{\Lambda}, x_{3}=0.25$; solid line, correlated using NRTL model.

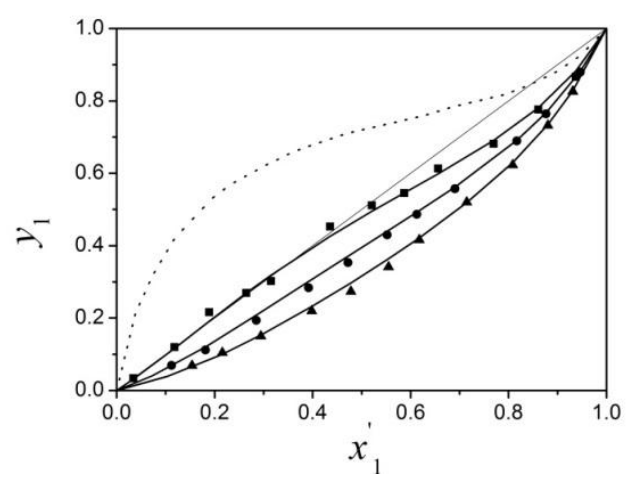

Fig. 3. Isobaric $y_{1}-x_{1}{ }^{\prime}$ diagram for the methanol (1) + DMC (2) + [BMIM][Cl] (3) ternary system at $101.3 \mathrm{kPa}$ : dotted line, IL-free system; $-x_{3}=0.1 ; \bullet, x_{3}=0.15 ; \boldsymbol{\Lambda}, x_{3}=0.2$; solid line, correlated using NRTL model.

Relative volatility $\alpha_{12}$ as an important indication could evaluate the separation effect of entrainer and its defined equation is:

$\alpha_{12}=\frac{y_{1} / x_{1}}{y_{2} / x_{2}}$

where $y_{1}\left(y_{2}\right)$ and $x_{1}\left(x_{2}\right)$ represent the vapor mole fraction and liquid mole fraction of the component $1(2)$, respectively.

Figs. 4-5 illustrate the relative volatility $\left(\alpha_{12}\right)$ of methanol to DMC with different ILs. It is obvious that in the whole-concentration region of methanol, with increasing the concentrations of ILs the relative volatility of methanol to DMC becomes smaller and smaller, until less than 1.0. Compared with [EMIM][Br], $[\mathrm{BMIM}][\mathrm{Cl}]$ has more 
outstanding separation effect.

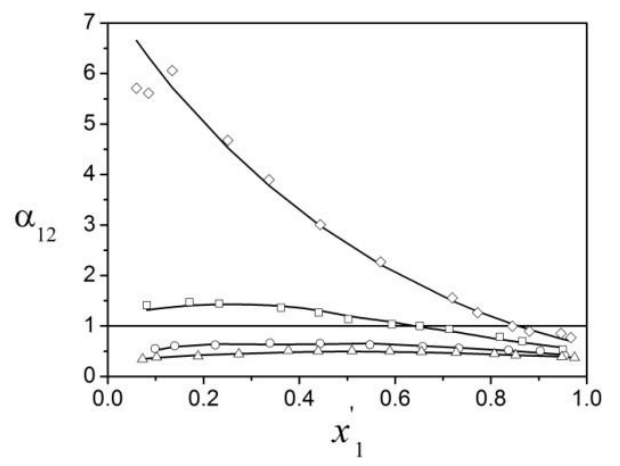

Fig. 4. Relative volatility $a_{12}$ of methanol (1) to DMC (2) at different mole fraction of [EMIM][Br] at $101.3 \mathrm{kPa}: \diamond, x_{3}=0 ; \square, x_{3}=0.1 ; \circ, x_{3}=0.2 ; \triangle, x_{3}=0.25$; solid lines, correlated using NRTL model.

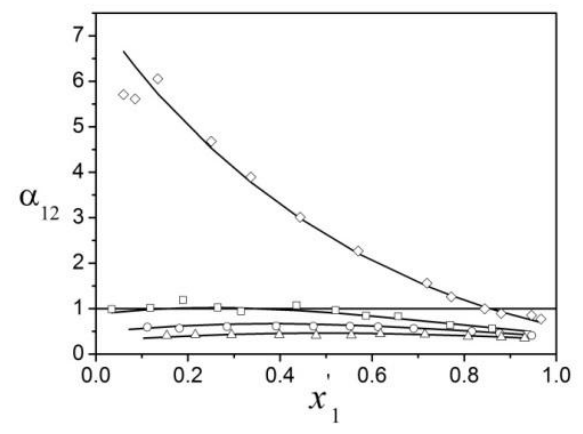

Fig. 5. Relative volatility $a_{12}$ of methanol (1) to DMC (2) at different mole fraction of [BMIM][Cl] at $101.3 \mathrm{kPa}: \diamond, x_{3}=0 ; \square, x_{3}=0.1 ; \circ, x_{3}=0.15 ; \triangle, x_{3}=0.2$; solid lines, correlated using NRTL model.

The influence of the two ILs [EMIM][Br] and [BMIM][Cl] on the VLE behavior of the methanol + DMC system might be attributed to the different attractive interactions between ILs and solvents. The ILs could be regarded as organic molten salts, so they are polar compounds. The polarity of methanol is stronger than that of DMC as indicated in table 8 which shows the size of the polarity of the two solvents expressed in $\mathrm{E}_{\mathrm{T}}(30)$. According to the principle of "like-dissolves-like", the attractive interaction of IL with methanol is stronger than that with DMC, resulting in that DMC is more volatile and the relative volatility of DMC to methanol is enhanced. In terms of the 
different separation effects of $[\mathrm{BMIM}][\mathrm{Cl}]$ and $[\mathrm{EMIM}][\mathrm{Br}]$, as the electronegativity of $[\mathrm{Cl}]^{-}$is stronger than that of $[\mathrm{Br}]^{-}$and methanol has a functional group $-\mathrm{OH}$ which is not only electron acceptor but also electron donor, the interaction between methanol and $[\mathrm{Cl}]^{-}$is stronger than that between methanol and $[\mathrm{Br}]^{-}$, thus separation effect produced by IL with the $[\mathrm{Cl}]$ anion is stronger. For cation, ILs with a short carbon chain have a stronger interaction with methanol when they have the same anion [21]. In other words, ethyl-based ILs have a stronger interaction with methanol than butyl-based ILs. However, in this work, the separation effect of [EMIM][Br] is weaker than $[\mathrm{BMIM}][\mathrm{Cl}]$, which might be ascribed to the relative leading role of anion.

\section{Table8}

$\mathrm{E}_{\mathrm{T}}(30)$ for methanol and DMC.

\begin{tabular}{ll}
\hline Component & $\mathrm{E}_{\mathrm{T}}(30) /(\mathrm{kcal} / \mathrm{mol})$ \\
\hline methanol & $55.4^{\mathrm{a}}$ \\
DMC & $38.2^{\mathrm{a}}$ \\
\hline
\end{tabular}

${ }^{\mathrm{a}}$ From ref. [30]

The separation effect of $[\mathrm{BMIM}][\mathrm{Cl}]$ on the methanol and $\mathrm{DMC}$ mixture is compared with other ILs reported in previous literature, including [OMIM] $\left[\mathrm{BF}_{4}\right]$ [20], [BMIM][OTf] [21], [EMIM][OTf] [21], 1-methyl-3-methylimidazolium dimethylphosphate $\quad([\mathrm{MMIM}][\mathrm{DMP}]) \quad[22], \quad$ 1-ethyl-3-methylimidazolium diethylphosphate ([EMIM][DEP]) [22], 1-butyl-3-methylimidazolium dibutylphosphate ([BMIM][DBP]) [23], [EMIM]TCB [24], [BMIM][BF $]$ [25], EMISE [25]. The minimum mole fractions of these ILs to break the azeotrope are 0.2, $0.133,0.202,0.074,0.09,0.096,0.08,0.1$ and 0.1 , respectively. This shows that the separation effect of $[\mathrm{BMIM}][\mathrm{Cl}]$ outperforms that of $[\mathrm{OMIM}]\left[\mathrm{BF}_{4}\right],[\mathrm{BMIM}][\mathrm{OTf}]$ 
and $[$ EMIM] $][\mathrm{OTf}]$ but is inferior to that of $[\mathrm{MMIM}][\mathrm{DMP}],[\mathrm{EMIM}][\mathrm{DEP}]$, $[\mathrm{BMIM}][\mathrm{DBP}][\mathrm{EMIM}] \mathrm{TCB},[\mathrm{BMIM}]\left[\mathrm{BF}_{4}\right]$ and EMISE. However, the price of $[\mathrm{BMIM}][\mathrm{Cl}]$ is cheaper and its synthesis and purification is easier than all the other reported ILs. So, [BMIM][Cl] may be a more suitable entrainer for the separation of methanol and DMC azeotropic mixture.

\section{Conclusions}

In this work, the isobaric VLE data for the ternary systems of methanol (1) + DMC $(2)+[$ EMIM $][\mathrm{Br}](3)$ and methanol (1) + DMC (2) + [BMIM] $[\mathrm{Cl}]$ (3) were measured at $101.3 \mathrm{kPa}$. The experimental data were well correlated using the NRTL model. Both ILs could enhance the relative volatility of DMC to methanol and break the azeotrope. But the separation effect of $[\mathrm{BMIM}][\mathrm{Cl}]$ was stronger than that of $[\mathrm{EMIM}][\mathrm{Br}]$. When mole fraction of $[\mathrm{BMIM}][\mathrm{Cl}]$ calculated by NRTL model was about 0.1168 , the azeotropic point disappeared. The conclusion is that [BMIM][Cl] could be a potential entrainer to separate the azeotrope system of methanol + DMC.

\section{Acknowledgement}

This work is financially supported by National Science Foundation of China (Project No. 21076126), National Science Foundation of China (Project No. 21576166), and Liaoning Province Science Foundation of China (Project No. 2014020140).

List of symbols
$\mathrm{A}_{i}, \mathrm{~B}_{i}, \mathrm{C}_{i}$
Antoine constants of component $i$
$\Delta g_{\mathrm{ij}}, \Delta g_{\mathrm{ji}}$
binary energy parameter of NRTL model
$x_{1}{ }^{\prime}$
mole fraction of methanol in liquid phase on an IL-free basis 
Greek letters

$\alpha_{12}$

$\alpha_{\mathrm{ij}}$

$\gamma_{i}$

$\gamma_{i}^{\text {exptl }}$

$\gamma_{i}^{c a l c d}$

$\delta$

$\sigma$ mole fraction of solvent $i$ in the liquid phase

mole fraction of solvent $i$ in the vapor phase

equilibrium temperature

total pressure in the equilibrium system

Saturated vapor pressure of component $i$

relative volatility of component 1 to component 2

non-randomness parameter of NRTL model

activity coefficient of component $i$

the activity coefficient of component $i$ measured by experimental data

the activity coefficient of component $i$ calculated with the NRTL model

mean absolute deviation

standard deviation 


\section{References}

[1] P. Tundo; M. Selva. The Chemistry of Dimethyl Carbonate. Acc. Chem. Res 35 (2002) 706-716.

[2] P. Rounce; A. Tsolakis; P. Leung. A Comparison of Diesel and Biodiesel Emissions Using Dimethyl Carbonate as an Oxygenated Additive. Energy Fuels 24 (2010) 4812-4819.

[3] K. Hsu, Y. Hsiao, and I. Chien. Design and Control of Dimethyl Carbonate Methanol Separation via Extractive Distillation in the Dimethyl Carbonate Reactive Distillation Process. Ind. Eng. Chem. Res. 49 (2010) 735-749.

[4] J. Tian, C. Miao, J. Wang, F. Cai, Y. Du, Y. Zhao. Efficient synthesis of dimethyl carbonate from methanol, propylene oxide and $\mathrm{CO}_{2}$ catalyzed by recyclable inorganic base/phosphonium halidefunctionalized polyethylene glycol. Green Chem. 9 (2007) $566-571$.

[5] B. Yang, D. Wang, H. Lin, J. Sun, X. Wang. Synthesis of dimethyl carbonate from urea and methanol catalyzed by the metallic compounds at atmospheric pressure. Catal. Commun. 7 (2006) 472-477.

[6] Michael A. Pacheco, Christopher L. Marshall. Review of Dimethyl Carbonate (DMC) Manufacture and Its Characteristics as a Fuel Additive. Energy \& Fuels 24 (2010) 4812-4819.

[7] P. Tundo, L. Rossi, A. Loris. Dimethyl Carbonate as an Ambident Electrophile. J. Org. Chem. 70 (2005) 2219-2224.

[8] Z. Zhang, F. Pan, Q.Zhang, T. Zhang, L. Zhang, K.Wu, W. Li. Isobaric 
Vapor-Liquid Equilibria for Ethyl Acetate + Methanol +Ionic Liquids Ternary Systems at 101.3 kPa. J Chem. Eng. Data 61 (2016) 772-779.

[9] S. M. Walas. Phase Equilibria in Chemical Engineering;Butterworth: Boston, 1985.

[10] M. F. Doherty, M. F. Malone. Conceptual Design of Distillation Systems; McGraw-Hill: New York, 2001.

[11] Z. Zhang, D. Huang, M. Lv, P. Jia, D. Sun, W. Li. Entrainer selectin for separating tetrahydrofuran/water azeotropic mixture by extractive distillation. Sep. Purif. Technol. 122 (2014) 73-77.

[12] S. Ohe, K. Yokoyama, S. Nakamura. Salt effect in Vapor-Liquid Equilibriums of Methanol-Ethyl acetate-Calcium Chloride System. J Chem. Eng. Data 16 (1971) $70-72$.

[13] M. C. Iliuta, F. C. Thyrion. Salt Effect on the Isobaric Vapor-Liquid Equilibrium of the Methyl Acetate + Methanol System. J Chem. Eng. Data 41(1996)713-717

[14] M. Topphoff, J. Kiepe, J. Gmehling. Effects of Lithium Nitrate on the Vapor-Liquid Equilibria of Methyl Acetate + Methanol and Ethyl Acetate + Ethanol. J Chem. Eng. Data 46 (2001) 1333-1337.

[15] I. Nagata. Isobaric Vapor-Liquid Equilibria for the Ternary System Chloroform-Methanol-Ethyl Acetate. J Chem. Eng. Data 7 (1962) 367-373.

[16] M. C. Martin, M. J. Cocero, F. Mato. Vapor-liquid equilibrium data, at 298.15 K, for six binary systems containing methyl acetate or methanol, with acetonitrile, nitromethane or nitroethane. Fluid Phase Equilib. 14 (1992) 243-252. 
[17] K. Nakashima, F. Kubota, T. Maruyama. Feasibility of Ionic Liquids as Alternative Separation Media for Industrial Solvent Extraction Processes. Ind. Eng. Chem. Res. 44 (2005) 4368-4372.

[18] X. han and Daniel W. Armstrong. Ionic Liquids in Separations. Acc. Chem. Res. 40 (2007) 1079-1086.

[19] Z. Zhang, A. Hu, T. Zhang, Q. Zhang, M. Sun. Separation of methyl acetate + methanol azeotropic mixture using ionic liquids as entrainers. Fluid Phase Equilib. $401(2015) 1-8$.

[20] Q. Li, W. Zhu, Y. Fu, H. Wang, L. Li. Isobaric Vapor Liquid Equilibrium for Methanol + Dimethyl Carbonate + 1-Octyl-3-methylimidazolium Tetrafluoroborate. J. Chem. Eng. Data 57 (2012) 1602-1606.

[21] Q. Li, S. Zhang, B. Ding, L. Cao, P. Liu. Isobaric Vapor-Liquid Equilibrium for Methanol + Dimethyl Carbonate + Trifluoromethanesulfonate-based Ionic Liquids at 101.3kPa. J. Chem. Eng. Data 59 (2014) 3488-3494.

[22] F. Cai, X. Wu, C. Chen, X. Chen. Isobaric vapor-liquid equilibrium for methanol + dimethyl carbonate + phosphoric-based ionic liquids. Fluid Phase Equilib. 352 (2013) 47-53.

[23] X. Chen, F. Cai, X. Wu, C. Asumana. Isobaric Vapor-Liquid Equilibrium for Methanol + Dimethyl Carbonate + 1-Butyl-3-methylimidazolium Dibutylphosphate. J. Chem. Eng. Data 58 (2013) 1186-1192.

[24] Ales Blahut, Vladimír Dohnal. Ionic liquid 1-ethyl-3-methylimidazolium tetracyanoborate: An efficient entrainer to separate methanol $\mathrm{p}$ dimethyl carbonate 
azeotropic mixture. Fluid Phase Equilib. 423 (2016) 120-127.

[25] Hyeon-Deok Kim, In-Chan Hwang, and So-Jin Park. Isothermal Vapor-Liquid Equilibrium Data at $\mathrm{T}=333.15 \mathrm{~K}$ and Excess Molar Volumes and Refractive Indices at $\mathrm{T}=298.15 \mathrm{~K}$ for the Dimethyl Carbonate + Methanol and Isopropanol +water with Ionic Liquids. J. Chem. Eng. Data. 55 (2010) 2474-2481.

[26] P. Wang, S. Liu, L. Lu, X. Ma, Y. He, Y. Deng. Separation of dibutyl carbonate/butyl carbamate close-boiling mixture using imidazolium-based ionic liquids. RSC. Adv. 5 (2015) 62110-62115.

[27] W. Hunsmann, Verdampfungsgleichgewicht von Ameisensaure/Essigsaureund von Tetrachlorkohlenstoff/Perchlorathylen-Gemi-schen, Vapourisation equilibria of formic acid/acetic acid and carbon tetrachloride/perchloroethylene mixtures. Chem. Ing. Tech. 39 (1967) 1142-1145.

[28] Stephenson, R. M.; Malanowskj, S. Tge Handbook of the Thermodynamics of Organic Compounds; Elsevier: New York, 1987.

[29] H. Renon, J. M. Prausnitz, Local composition in thermodynamic excess functions for liquid mixtures. AIChE J. 14 (1968) 135-144.

[30] Christian Reichardt. Solvatochromic Dyes as Solvent Polarity Indicators. Chem. Rev. 94 (1954) 2319-2358. 